\section{L-carnitine supplementation for the management of fatigue in patients with hypothyroidism on levothyroxine treatment}

\section{Dear Editor,}

We have read with interest the nice article by An et al. [1], and thank them for having cited some papers of our team, but not one [2]. That paper [2] not only mentions the wide range of patients who may benefit of L-carnitine supplementation, but also underscores that on some thyroid hormone targets L-carnitine acts as an antagonist, while on others as an agonist. We would like to discuss some aspects that were missed there [1].

We start with somewhat minor comments. First, we continue to confirm that L-carnitine has minimal, if any, side-effects. Second, the formulation of L-carnitine we use (one ampoule of $1 \mathrm{mg}$ given twice a day) is more practical than the one used by An et al. (3 tablets of $0.33 \mathrm{~g}$ twice a day for a total of $1,980 \mathrm{mg} / \mathrm{d}$ ) [1].

Concerning the relevant comments, we think that the setting or framework for this study is the symptomatology of hypothyroidism which persists despite adequate daily doses of L-T4, and that concerns approxi-

Salvatore Benvenga ${ }^{1), 2), 3)}$ and Alessandro Sindoni ${ }^{4)}$

1) Section of Endocrinology, Department of Clinical and Experimental Medicine, University of Messina, School of Medicine, 98125 Messina, Italy

2) Master Program on Childhood, Adolescent and Women's Endocrine Health, University of Messina, School of Medicine, 98125 Messina, Italy

3) Interdepartmental Program on Molecular \& Clinical Endocrinology, and Women's Endocrine Health, University hospital, A.O.U. Policlinico G. Martino, 98125 Messina, Italy

4) Section of Radiological Sciences, Department of Biomedical and Dental Sciences and of Morphological and Functional Images, University of Messina, 98125 Messina, Italy

Submitted Aug. 2, 2016; Accepted Aug. 12, 2016 as EJ16-0374 Released online in J-STAGE as advance publication Aug. 30, 2016 Correspondence to: Alessandro Sindoni, M.D., Dipartimento di Scienze Biomediche, Odontoiatriche e delle Immagini Morfologiche e Funzionali. Sezione di Scienze Radiologiche, A.O.U. Policlinico "G. Martino", Pad. E, IV Piano. Via Consolare Valeria, 1 - 98125 Messina, Italy.

E-mail: alessandrosindoni@alice.it

(C) The Japan Endocrine Society mately $10 \%$ of hypothyroid patients, especially those with no remnant thyroid tissue (i.e., post-radioiodine, post-thyroidectomy hypothyroidism) [3]. This residual symptomatology consists essentially in physical and/or mental fatigue, and can be addressed by adding L-T3 to L-T4 [3].

Within the limits of words and references permitted by the journal and not to give complete details that would preclude publication of a full paper, we would like to give some information in support of the An and colleagues' article [1]. We have a number of hypothyroid patients who have taken $2 \mathrm{~g} / \mathrm{d} \mathrm{L}$-carnitine even for longer than 12 weeks, and we confirm the benefit in terms of physical and mental fatigue. The benefit is observed particularly in premenopausal women with postoperative hypothyroidism. Thus, it is not surprising for us that women and postoperative hypothyroidism accounted for $100 \%$ and approximately two-thirds of the subgroup that improved, but approximately $75 \%$ and $40 \%$ of the subgroup who did not (table 3 of ref. 1).

A mechanistic explanation for the efficacy of L-carnitine we wish to offer has to do with previous research on the modulation of L-carnitine on glucocorticoid action [4]. L-carnitine promotes nuclear translocation of glucocorticoid receptor- $\alpha(\mathrm{GR} \alpha)$, an important activating step of the glucocorticoid signalling. After nuclear translocation, homodimers of the activated GR $\alpha$ modulate the transcription of many responsive genes by binding to specific DNA-associated glucocorticoid-responsive elements (GREs) in the promoters of these genes. Similarly to glucocorticoids, L-carnitine suppressed the release of tested cytokines (tumor necrosis factor- $\alpha[\mathrm{TNF} \alpha]$ and interleukin-12 release by the tested cells (human primary monocytes) [4]. The glucocorticoid-mimetic activity of L-carnitine, resulting from stimulated transcriptional activity of GR $\alpha$, would have not been predicted by the inhibiting effect of L-carnitine on glucorticoid entry into cells [4]. Now, considering that (i) cytokines are pathogenetically involved in fatigue and other neuropsychological disorders, (ii) GR $\alpha$-mediated action of glucococorticoids results in "energizing" effects [5], and (iii) glucocorticoids extert a well-known inhibition of TSH secretion, it cannot be coincidental that the improved subgroup had an almost 3-fold lower concentration of TSH compared to the non-improved subgroup [1]. 


\section{References}

1. An JH, Kim YJ, Kim KJ, Kim SH, Kim NH, et al. (2016) L-carnitine supplementation for the management of fatigue in patients with hypothyroidism on levothyroxine treatment: a randomized, double-blind, placebo-controlled trial. Endocr J 63: 885-895.

2. Benvenga S, Amato A, Calvani M, Trimarchi F (2004) Effects of carnitine on thyroid hormone action. Ann NY Acad Sci 1033: 158-167.

3. Wiersinga WM, Duntas L, Fadeyev V, Nygaard B,
Vanderpump MP (2012) 2012 ETA Guidelines: The Use of L-T4 + L-T3 in the Treatment of Hypothyroidism. Eur Thyroid J 1: 55-71.

4. Alesci S, De Martino MU, Mirani M, Benvenga S, Trimarchi F, et al. (2003) L carnitine: A nutritional modulator of glucocorticoid receptor functions. FASEB J 17: 1553-1555.

5. Plihal W, Krug R, Pietrowsky R, Fehm HL, Born J (1996) Corticosteroid receptor mediated effects on mood in humans. Psychoneuroendocrinology 21: 515-523. 